\title{
INDIVÍdUOS, CIDADÃos E O COLETIVO NA POESIA DE ARQUílOCO*
}

\author{
Paula da Cunha Corrêa ${ }^{1}$
}

\section{Resumo}

Neste trabalho são examinados os conceitos e as expressões para os indivíduos (nomes próprios e gentílicos), os cidadãos (astoí, polítai), e a coletividade (dēmos, gentílicos) nos fragmentos de Arquíloco.

\section{Palavras-chave}

Arquíloco; cidadãos; coletividade; poesia grega arcaica.

\begin{abstract}
This paper examines the concepts and terms employed for individuals (proper and ethnic names), citizens (astoi, politai), and the collectivity (dèmos, ethnic names) in the fragments of Archilochus.
\end{abstract}

\section{Keywords}

Archilochus; citizens; collectivity; Archaic Greek poetry.

\footnotetext{
* Este artigo foi apresentado no XI Congresso da Sociedade Brasileira de Estudos Clássicos (SBEC) na Universidade de São Paulo em 04 de dezembro de 2017.

1 Professora Associada, Universidade de São Paulo, São Paulo, Brasil. E-mail: correa@usp.br
} 
Na obra de Arquíloco de Paros encontramos uma profusão de indivíduos, sejam esses personagens (baseados em pessoas históricas ou não), heróis e deuses. Dentre os deuses figuram Zeus ${ }^{2}$, Demeter $^{3}$, Dioniso $^{4}, \mathrm{Apolo}^{5}$,

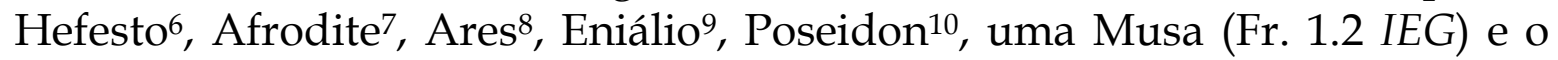
titã Tântalo (Fr. 91.14 IEG). Entre os heróis, contamos Dianira (Fr. 286-8 IEG) e Héracles (Fr. 259, 286-9, 324.2 IEG), Erimas (Fr. 25. 8 IEG), Pirro e Eurípilo (Fr. 304? IEG), Télefo (P.Oxy. 4708) e os seres como Nessos (Fr. 286, 288), e Aqueloos (Fr. 286-7 IEG).

Um provável companheiro e amigo do poeta, que não é poupado de sua sátira, é Glauco. Pois com o descobrimento e publicação da lápide de Glauco em Tasos (SEG 14.565; $1 \mathrm{~T}$ Gerber, 1999) confirmou-se que, atrás da personagem citada seis vezes na obra de Arquíloco ${ }^{11}$, havia uma pessoa histórica, satirizada no fragmento 117 IEG por seu penteado elaborado:

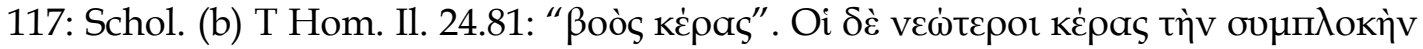

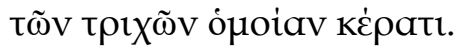

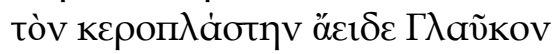

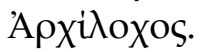

Schol. (b) T Hom. Il. 24.81: "Corno de boi". Os mais recentes empregam "corno" para o trançado de cabelos semelhante a cornos.

\section{Canta o cornudo, Glauco}

Porém, os mais célebres alvos dos jambos do poeta, cujos nomes falantes podem ou não ter visado a uma família de Paros são Licambes'12, Anfimedo (Fr. 196a.10 IEG) e suas filhas, Neobula (Fr. 118, 196a.24 IEG) e uma mais jovem cujo nome próprio ou codinome não figura nos versos que nos

2 Fr. 25.6, 91.30, 91?, 94.2, 98.7, 13, 122.2, 131.2, 154.5, 157.2, 177.1, 197, 230, 298.1 IEG.

3 Fr. 169, 322.1 IEG.

4 Fr. 120.1, 251.1 IEG.

${ }^{5}$ Fr. 26.5 IEG.

${ }^{6}$ Fr. 9.11, 108 IEG.

7 Fr. 112.11, 113.6? IEG.

${ }^{8}$ Fr. 3.2, 10.8?, 18, 110 IEG.

9 Fr. 1 IEG.

${ }^{10}$ Fr. 12.1, 192 IEG.

11 Fr. 15, 48.7, (96), 105.1, 117, 131.1 IEG.

12 Fr. 38, 54.8, 60.2?, 71.1, (172-81 Test.), 172.1 IEG. Veja também o patronímico de Licambes, Dotades (Fr. 57.7, 151.3? IEG). Para os possíveis significados do nome "Licambes", veja Pickard-Cambridge (1927: 15), West (1974) e Miralles-Pòrtulas (1983). 
restaram (Fr. 196a IEG). Além desses, há uma riqueza de tipos, como o glutão Carilau filho de Erasmo (Fr. 168 IEG):

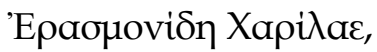

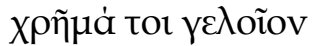

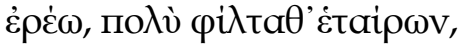

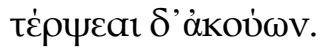 \\ Carilau, filho de Erasmo (Amável?), \\ uma coisa engraçada a ti \\ contarei, caríssimo companheiro, \\ e terás prazer em ouvi-la.
}

Assim como Licambes, Neobula, Anfimedo, Cerícides (Fr. 185 IEG), Pasífile (Fr. 331 IEG, que é "amiga de todos" pasí-phílē) e Leófilo (Fr. 115 IEG), Carilau (Fr. 168 IEG), a quem esses versos se dirigem, parece ter sido um nome significativo ou um codinome ${ }^{13}$.

No início do fragmento, que pode ter sido também o início do poema, o "eu" dirige-se a seu destinatário através de um patronímico e nome que sugerem tratar-se de alguém que é ou que faz a "alegria das tropas" (kháris + laós). Nesta mesma linha, o patronímico "filho de Erasmon", apesar de imitar a dicção elevada da épica, também é sugestivo. Alguns o traduzem como "filho de Amável", "do Agradável", mas o nome também poderia assumir conotações mais eróticas como o traduz Bonnard ("Fils de l'Amour"14) e, nesse caso, se levarmos em conta os testemunhos acima referidos, segundo os quais Carilau é caracterizado como glutão, talvez a "coisa engraçada" seja uma história de gula, mas não por comida.

Nagy (1979: 91) comparou o nome de Aquiles (*Akhi-lāuos), aquele "cujo laós sofre" com *Kharí-lāuos, "aquele cujo laós se alegra". O patronímico é relacionado por Nagy com o "florescer da juventude que inspira poesia" (como em Anacreonte Fr. 375 PMG), assim como o verbo térpomai

\footnotetext{
13 Separados por asteriscos, mas num mesmo conjunto, Schneidewin (1838) dispunha os fragmentos 168, 170, 171, 169, e Bergk (1882): 168, 171, 170, 169. Seguiram Bergk (1882) na ordenação dos fragmentos Fick (1882), Hoffmann (1898) Diehl (19261, 19362, 19523), Treu (1959), Tarditi (1968) e Adrados (19903). Lasserre (LB 1968), porém, dispôs os fragmentos na ordem que foi adotada por West $\left(1971^{1}, 19892\right)$ e Gerber (1999). Os fragmentos não apresentam grandes problemas textuais, mas, dependendo da interpretação métrica, os editores os arranjam em forma estrófica, situando-os entre os epodos (West 1971'1, 19892; Gerber 1999) ou, seguindo Hefestião, entre os asinártetos. Cf. Itsumi (2007).

14 Tradução de Bonnard (1958): "Fils de l'Amour, Charilaos, jê veux te dire une chose plaisante, ô le plus cher dês amis, et tu serás ravi de l'entendre."
} 
("dar/receber prazer") "convencionalmente designa o efeito da poesia". Odisseu (Od. 9. 3-11) diz não haver nada mais repleto de kháris do que cear e ouvir o aedo, assim também Carilau desfrutará do prazer dos convivas, como o "mais querido dos companheiros". Nagy conclui que o epodo de Arquíloco (Fr. 168 IEG) dirigia-se a phíloi em um simpósio ${ }^{15}$.

Que esses nomes Erasmonida e Carilau sejam falantes é algo que se suspeita pelo menos desde Liebel (1812), e muitos observaram que essa é uma das características que o jambo arcaico partilha com a comédia antiga ${ }^{16}$. Um fragmento da comédia de Cratino (11 K-A) intitulada "Os Arquílocos" parece

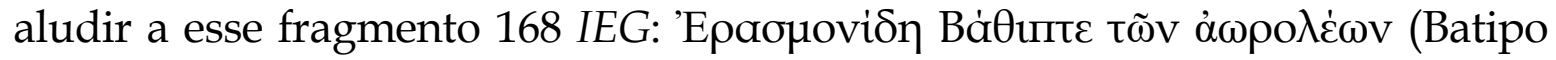
Erasmonida, dentre os desbarbados). O patronímico em Cratino "ridiculariza a natureza luxuriosa de Batipo"17 e o adjetivo aōróleios, que significa "o que é liso de forma não-natural", pode, por sua vez, aludir a adultos que se barbeiam para passarem por pré-púberes imberbes, na busca de amantes. É possível que esse fosse o mesmo tema explorado por Arquíloco.

A relação do falante ("eu") com Carilau não é evidente. Não sabemos se eram amigos ou se a designação do destinatário como o "mais querido dos companheiros" é irônica, e se o uso do patronímico em gêneros elevados é "honorífico e solene", nos jambos ele é frequentemente jocoso ${ }^{18}$. Rosen (2007: 26, n. 37) afirma:

Tem-se sugerido que muitos psógoi jâmbicos foram compostos para serem apresentados na presença de seus alvos, e nem sempre com o propósito real de feri-los. Essa noção supõe que o público, o poeta e o alvo faziam parte de um grupo relativamente fechado de phíloi que apreciava o entretenimento cômico de chistes criativos mútuos. ${ }^{19}$

O que seria essa "coisa engraçada"? Gentili (1998: 189) supõe uma censura jocosa, uma piada dirigida a um conviva no simpósio, e a coisa engraçada seria a "polifagia" de seu querido companheiro, o "apetite voraz" de Carilau²0.

15 Também para Kantzios (2005: 24) o poema 168 IEG de Arquíloco faria parte das "brincadeiras amistosas das reuniões sociais".

16 Veja, particularmente, Rosen (1988).

17 Cf. Meineke 1.22, Kock 1.15 apud Rosen (1988: 43).

18 Cf. Gentili e Catenacci (2007).

19 Cf. Nagy (1979: 244-45) que encontra fundamento para isso em Arquíloco 168 IEG.

${ }^{20}$ Hauvette (1905: 177) sugeria tratar-se de uma anedota, talvez seguindo Liebel (1812) que a identificava com a anedota do coríntio chamado Etíope (Arquíloco Fr. 293 IEG). Segundo Martino e Vox (1996: 645), o conteúdo prometido é uma história bufa, para Treu (1959), "não é fábula, não é mito, mas talvez um acontecimento real". Em meio a tantas dúvidas, Bowie (2001: 19) observa que o que há de mais claro no fragmento 168 IEG de Arquíloco, apesar da 
Mas há um grande número de apóstrofes nos versos de Arquíloco e, particularmente, na introdução de fábulas, o que torna interessante a sugestão de que a "coisa engraçada" fosse uma fábula. O coro de velhos na Lisístrata inicia uma fábula de forma muito semelhante quando diz:

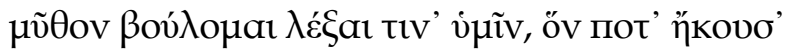
av̉iòs हैंtu חaĩs ఢ̋v.
v. 784/5 ỡt
Uma história quero contar a vocês, que eu mesmo ouvi um dia, ainda criança.
Era uma vez um rapazinho, Melânio ...21

E nas Vespas (v. 566) de Aristófanes, Filocleão refere-se às fábulas esópicas como "algo engraçado" (ti géloion)22: "Uns nos contam mitos, outros algo engraçado de Esopo" 23 . Conforme Rankin (1977: 92):

No fragmento $162 \mathrm{~T}$ (= 168 IEG) Arquíloco também recorre à técnica e ao maneirismo do contador de histórias (...). O poeta serve-se de frases épicas, mas o estilo é o do lógos, um homem contará uma história para outro, seja uma anedota sobre pessoas reais, ou uma fábula que trata de "certos animais" (...)

Outro glutão nomeado na poesia de Arquíloco é Etíope de Corinto que, segundo Ateneu ( Deipn. 4. 167d = Fr. 293 IEG), teria trocado o lote de terra ao qual teria direito em Siracusa por um bolo de mel. Nada mais sabemos além disso.

Há também três personagens, Eurimas, Melesandro (?) e o boiadeiro Falângio, mencionadas no fragmento papiráceo que parece discorrer sobre as preferências sexuais de Melesandro e do boiadeiro nos primeiros quatro versos (Fr. 25 P. Oxy. 2310 fr. 1 col. i.40-48, ed. Lobel):

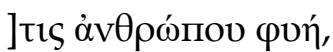

$$
\begin{aligned}
& \dot{\alpha} \lambda \lambda^{\prime} \alpha \ddot{\alpha} \lambda \lambda \text { os } \alpha \dot{\alpha} \lambda \omega \mathrm{t} \mathrm{ka] \rho \delta ínv} \mathrm{iaívetat.}
\end{aligned}
$$

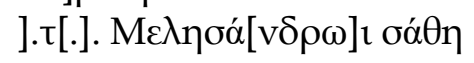

possível crítica dirigida a Carilau, é o modo "como o poeta chama atenção para o seu papel de contador de histórias".

${ }^{21}$ Tradução de Duarte (2005). Zanetto (2001: 68-9) cita esse e outro exemplo em Lisístrata (vv. 805-20). Uma leitura diversa é a de Batezzatto (2009: 139) que, ao reconhecer ecos homéricos no poema de Arquíloco Fr. 168 IEG, sugere que não se trata de início de fábula, mas de uma paródia da Ilíada 1.1-2.

${ }^{22}$ Zanetto (2001: 69).

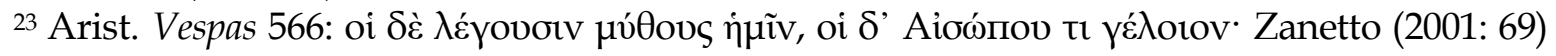
cita ainda Vesp. 1259-1260. 


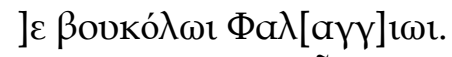

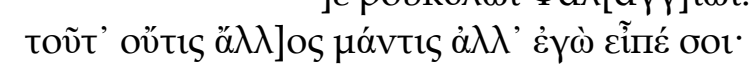

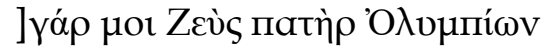

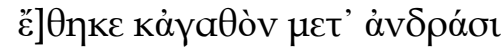

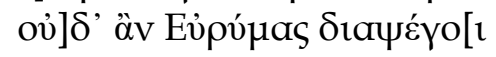

... natureza humana, mas, cada um a seu modo] contenta o [co]ração, para Melesa[ndro (?)] pênis ...para o boiadeiro Fal[âng]io... isto foi nenhum (?)] adivinho senão eu que te disse:

..].pois a mim, Zeus, pai dos olímpios ...f]ez, e nobre entre os homens ...n]em Eurimas reprovaria...

Dentre os reis e líderes que figuram na poesia de Arquíloco, o mais célebre é Giges, rei da Lídia. O poema (Fr. 19 IEG) parece ser estruturado em forma de priamel, um recurso retórico frequente na poesia grega arcaica em que uma série de valores ou objetos caros à maioria são primeiro enumerados e depois, descartados em favor de uma opção particular. Por exemplo, no fragmento 114 IEG de Arquíloco o "eu" primeiro descreve o grande general que depois é rejeitado em detrimento rejeita do general de sua preferência: pequeno, cambaio e cheio de coragem. É verossímil que também no fragmento 19 IEG de Arquíloco, após uma sequência de objetos preteridos, o "eu" expusesse a sua preferencia:

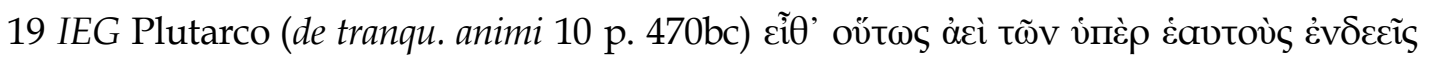

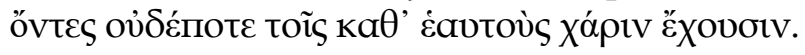

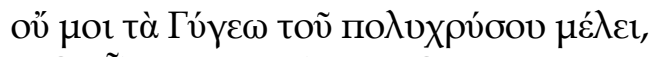

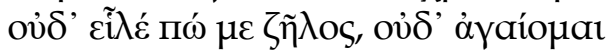

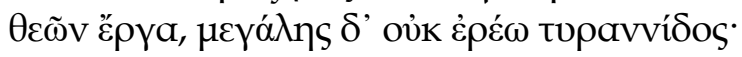

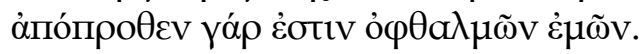

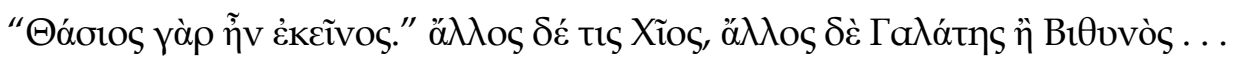

19 IEG Plutarco (de tranqu. animi 10 p. 470bc) "Assim, como sempre carecem do que está além deles, jamais são gratos por o que lhes cabe.

Não me interessa o que é de Giges, coberto de ouro, jamais fui tomado pela a inveja, não almejo as obras dos deuses, nem amo a grande tirania, pois estão longe dos meus olhos. 
“Pois ele era um tásio" (alguém dirá). Mas, outros, um quio, ou galácio ou bitínio,..

Plutarco cita esses quatro versos em seu tratado Sobre a tranquilidade da alma (10.470 b-c) como exemplo de uma atitude que, a seu ver, pode conduzir à "paz de espírito" (euthymía): "manter os olhos voltados o máximo para si e as suas coisas e, caso isso seja impossível, observar os mais carentes e não, como a maioria, comparar-se com os superiores"24. Segundo Plutarco (loc. cit.), falta ao povo (hoi polloî) essa atitude, "pois a maioria, sempre ciente do que carece, nunca é grata pelo que lhe cabe" 25 .

Aristóteles também cita o início do poema na Retórica ( $\Gamma 17$ p.1418b23), revelando um fato que Plutarco omitiu (ou ignorava): quem fala nestes versos de Arquíloco é Caronte, um carpinteiro. No que concerne ao èthos, Aristóteles (loc. cit.) comenta a necessidade de atribuir o discurso a um terceiro quando se deseja falar de si próprio (para evitar inveja, um discurso longo ou contradição), ou quando se quer falar de outro, para evitar ser acusado de ralhar ou ser grosseiro. São dados como exemplos dois discursos de Isócrates ${ }^{26}$, o início de dois poemas de Arquíloco (Fr. 19, 122 IEG) e versos da Antígona (vv. 683-709) de Sófocles.

Nos quatro trímetros, quatro objetos são preteridos e uma justificativa é dada no final. No primeiro verso, o epíteto polýkhrysos ("o de muito ouro") qualifica Giges e sugere o que são essas coisas que Caronte alega não lhe interessar27. Heródoto (I.12) conta como Giges tornou-se rei da Lídia (687-652 a. C.) e que Arquíloco, contemporâneo do rei, mencionou-o em seus trímetros jâmbicos. Os versos do fragmento 19 IEG foram logo identificados como sendo aqueles aos quais Heródoto se referia, e o testemunho do historiador serviu como mais uma evidência para a datação do poeta 28.

A opulência dos reinos asiáticos era proverbial, assim como o tesouro de Giges $^{29}$. Embora "Caronte" diga que tais riquezas não lhe interessam, assim

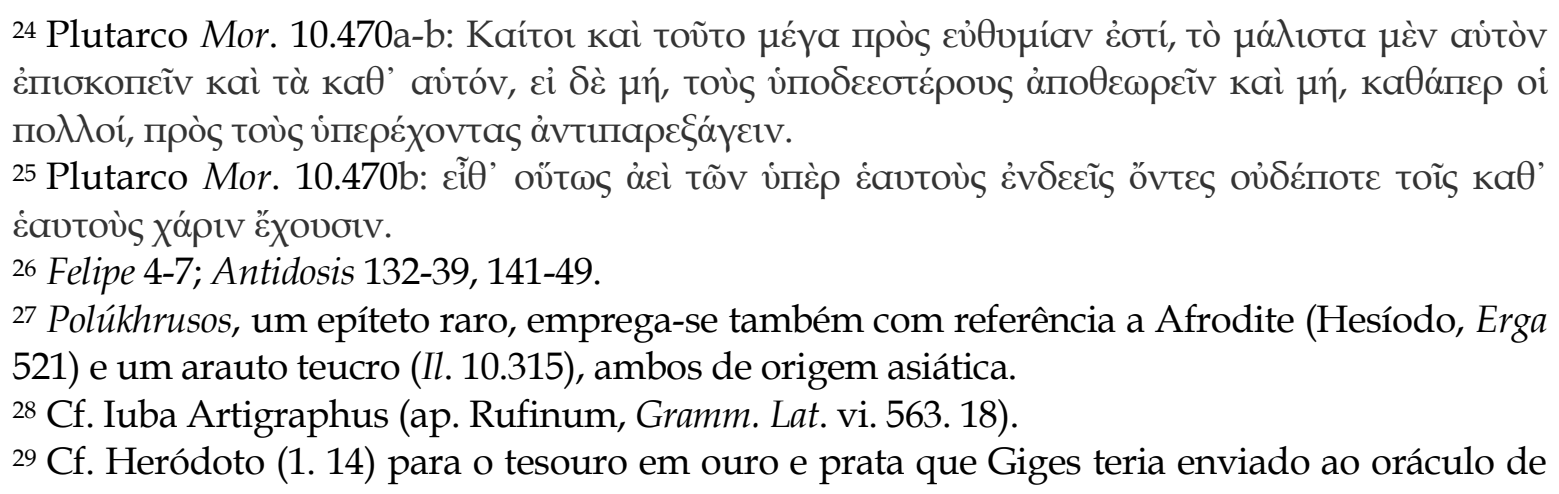


como os feitos dos deuses e a tirania, a enfática repetição de negativas anafóricas e a construção "Não me interessa..." traem o seu desdém, como no fragmento sobre o escudo abandonado (Fr. 5 IEG: tí moi mélei aspìs ekeínē; "o que me importa aquele escudo?") 30 .

O segundo verso se inicia com a repetição anafórica da negação e o dzēlos que Caronte diz não se apoderar dele. Dzēlos, traduzido aqui por "inveja", nem sempre possuía conotação negativa, e o seu emprego com valor positivo era inclusive mais comum (Chantraine, 19992, s.v.; LSJ). Ao contrário de phthónos, $d z \bar{e} l o s$ e as demais palavras desse mesmo tema são geralmente empregadas como uma "admiração", "emulação", ou "zelo" (cf. zelus do latim tardio) ${ }^{31}$. O verbo agaíomai na terceira oração que tem por objeto "as obras dos deuses", pode significar "indignar-se por justa causa" 32 ou "admirar" / "invejar" (cf. LSJ), apresentando a mesma ambiguidade que $d z \bar{e} l o s^{33}$.

Na quarta frase Caronte alega: "a grande tirania não amo", e Hípias (FGH 6F6) ${ }^{34}$ diz ser esta a primeira menção à "tirania". O týrannos, termo de origem asiática, denomina o "senhor absoluto cujo poder não é limitado por leis"35. Mas em Arquíloco, como em outros textos arcaicos, a "tirania" pode corresponder a "reinado", e nesse caso a sua qualificação como "grande" (megálēs) não parece significar um poder "absoluto", mas um vasto ou extenso, como o dos grandes reinos asiáticos. Não sabemos se nesta época o termo týrannos possuía uma conotação negativa ${ }^{36}$. Mas no fragmento 23.20-21 IEG de Arquíloco, segundo os suplementos, alguém é exortado a "reinar" sobre a cidade e a "ser tirano" pois, assim, "por muitos homens será(s) invejado"

Delfos.

30 Todos ancepi são ocupados por sílabas longas e a "gravidade" transmitida pelo ritmo pode, nesse caso, ter efeito irônico.

31 Chantraine (19992, s.v.). Cf. Aristóteles (Rhet. 1388b) para a distinção entre phthónos ("inveja") e dzēlos ("emulação nobre"), mas Hesíodo (Erga 195) para dzēlos como "inveja", como na Odisseia (5.118) onde dzèlémones tem sentido negativo.

32 Cf. Od. 20. 16, Hesíodo Erga 333, Heródoto 8. 68.

33 Mas o que e de quem seriam essas "obras dos deuses" aos quais Caronte se refere? Na Ilíada (16. 120), ao perceber a intervenção divina nos feitos de Heitor, Ájax os chama de "érga theōn", ao passo que, na Odisseia (1. 338), "érga andrōn te theōn te" servem de matéria para as canções dos aedos. Talvez não seja em Arquíloco uma referência os feitos e oferendas de Giges (Gerber 1970: 22).

34 Apud Argum. in Soph. Oed.Reg. Cf. Et. Gud. (col. 537.26 Sturz), Et. Magn. (p.771.54 Gaisford); Schol. Aesch. Prom. 222 (Dindorf, p.17).

35 Chantraine (19992, s.v.).

36 Cf. Gerber (1970: 23), Andrews (1956: 20ss). Simônides (584 PMG) e fontes supra. 
$(d z] \bar{e} l o ̄ t o ́ s)^{37}$. Quer se trate de uma metáfora ou não, a tirania nesses versos é algo digno de cobiça e que suscita inveja (dzēlos), de modo comparável, no fragmento 19 IEG de Arquíloco o verbo empregado (eréō, forma jônica de eráō) expressa um desejo forte: "a grande tirania não amo"38.

No quarto verso a justificativa para as negações é a constatação realista do carpinteiro que diz que tudo isso está longe de seu alcance ("longe de meus olhos" $)^{39}$. Se o poema terminasse aqui, ofereceria um bom exemplo daquilo que prega Plutarco $(10.470 \mathrm{bc})$. A partir do sexto século a. C., o "ideal da tranquilidade cívica" fundada na apologia da moderação, do "meio" (tò méson), torna-se um tópos, "lugar comum" entre os poetas ${ }^{40}$. Mas se no século anterior Arquíloco faz o elogio da moderação em alguns poemas (como no fragmento 128 IEG), ele parece muito distante de um Sólon que diz recusar a tirania que lhe ofereceram ${ }^{41}$. Quase todos os comentadores de Arquíloco acreditam que haveria na fala de Caronte uma virada final, e oferecem diversas hipóteses ${ }^{42}$. Uma imitação tardia, um poema da Anacreontea (8), pode dar uma boa pista ${ }^{43}$ :

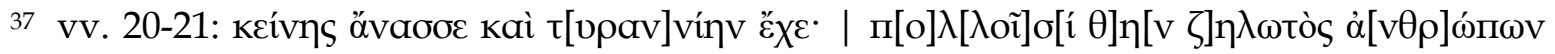
हैocau.

38 Para descrever Dioces, um "amante da tirania" (erastheis tyrannídos), Heródoto (1. 96. 2) emprega um particípio do mesmo tema.

${ }^{39} \mathrm{O}$ verbo (embora no singular) refere-se a todos os objetos anteriores, cf. De Falco e Coimbra (1941), Lasserre-Bonnard (1958), Tarditi (1968), Gerber (1970: 23); Fränkel (1975), BarronEasterling (1985) e West (1993).

40 Cf. Sólon Fr. 10. 2 IEG, Teógnis Fr. 219-20, 331-2, 335-6 IEG, Focílides Fr. 9 IEG. Cf. Píndaro P. 11.50 ss., onde o poeta afirma querer o que está em seu poder, censurando a tirania e fazendo o elogio "do meio" (tà mésa).

41 Cf. Sólon Fr. 4c, 6, 32, 33, 34 IEG, e para o conservadorismo aristocrático de Píndaro e Sólon, Gentilli (1988: 149).

42 Cf. Rankin (1977: 83), Fowler (1987: 72), Pippin-Burnett (1983: 67). Fränkel (1975: 138) sugere que Caronte, não se importando com o rei distante, censura um desonesto "novo-rico" local e cita como paralelo a crítica feita por Anacreonte (Fr. 388 PMG) a Artemon. Cf. Fränkel (1955: 57): "<wenn ich aber den NN in seinem übelerworbenen Reichtum und seiner unverdienten Herrlichkeit an meinem Neubau vorüberstolzieren sehe, so läuf mir doch die Galle über --" So sprach der Zimmermann Charon auf Thasos>. Cf. Horácio Ep. 4. Outro fragmento de Anacreonte (Fr. 361PMG), que desenvolve tema semelhante, é também comentado por Fränkel (1975: 301, n. 28): "eu não queria/ o corno de Amáltea,/ nem por cento e cinquenta anos/ ser rei de Tarteso."

$43 \mathrm{Um}$ fragmento de Anacreonte (Fr. 361PMG), que desenvolve tema semelhante, é também

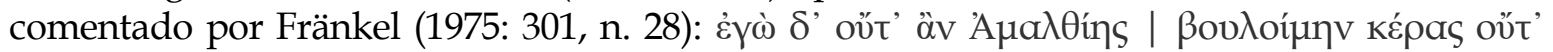

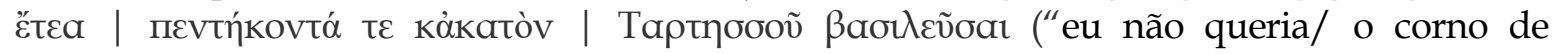
Amáltea,/ nem por cento e cinquenta anos/ ser rei de Tarteso"). 


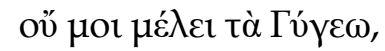

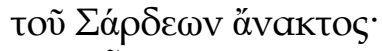

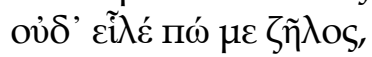

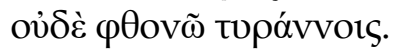

5

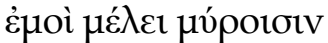

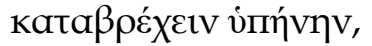

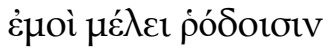

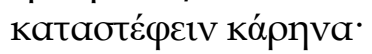

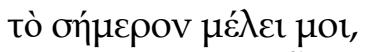

10

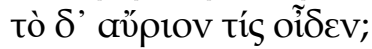

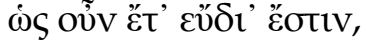

Kaì חĩve Kaì Kú $\beta \varepsilon v \varepsilon$

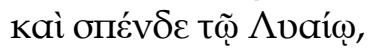

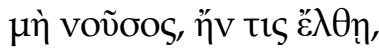

15

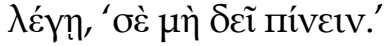

Não me interessa o que é de Giges,

rei de Sardes,

jamais fui tomado pela a inveja,

nem me ressinto da tirania.

5 Interessa-me encharcar

a barba com mirra,

interessa-me coroar

a cabeça com rosas,

interessa-me o agora.

10 Quem sabe do amanhã?

Então, enquanto ainda está claro,

bebe, joga dado

e liba ao Lieu

enquanto uma doença não vier

dizer: "não deves beber. ${ }^{44}$

Um outro líder político em Arquíloco é Leófilo. Segundo Aristóteles, Pol. 1305a, "antigamente, quando um "demagogo" (dèmagōgós, "líder do povo") era também chefe militar (stratēgós)", a constituição tornava-se uma tirania, "pois quase a maioria dos tiranos antigos surgiram dos demagogos" 45 . Isso

${ }_{44}$ Esse autor pode ter se apropriado dos primeiros versos de Arquíloco apenas como mote, e nada impede que o original tivesse uma continuação mais erótica ("não me interessa o ouro de Giges (...), mas a mulher que ..."), ou satírica, difamando um amigo ou inimigo. Para outras imitações ou paródias de Arquíloco Fr. 19 IEG, cf. A. P. 9.110, Gregório Naziano ad. animam suam 84 sg; Patr.Gr. 37.683, 1435 Migne.

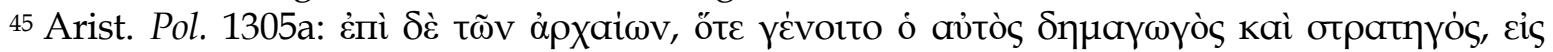

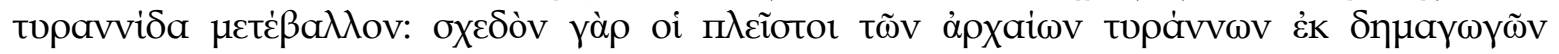
үeyóvaouv. "Tiranos" eram também os que obtinham poder real de forma "ilegítima", como o 
oferece uma possível via de leitura para o fragmento sobre Leófilo, cujo nome significa "caro ao exército" (leós + phílos):

Fr. 115 IEG Pseudo-Herodiano, de figuris (Rhet. Gr. viii.598.16 Walz, iii.97.8 Spengel)

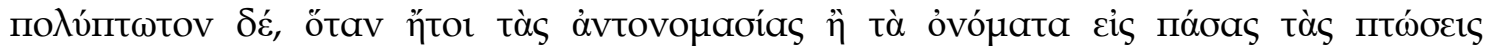

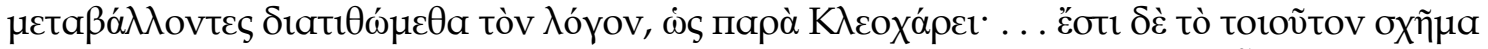

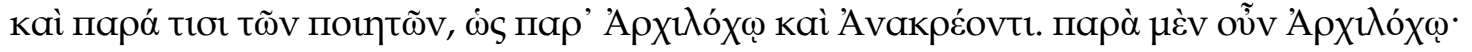

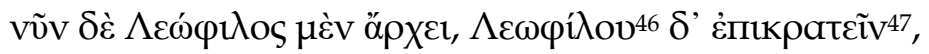

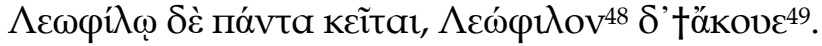

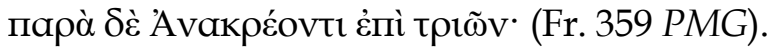

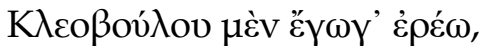

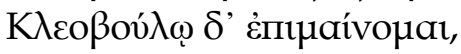

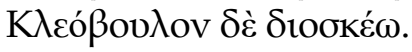

Pseudo-Herodiano, de figuris (Rhet. Gr. viii.598.16 Walz, iii.97.8 Spengel) “Ocorre um poliptoto quando arranjamos o discurso alterando os pronomes ou nomes em todos os casos, como, segundo Cleocares: (...) Há tal figura também em alguns poetas, como em Arquíloco e Anacreonte. Em Arquíloco:

E agora Leófilo governa, de Leófilo é o poder, em Leófilo tudo repousa e a Leófilo (escuta?) ${ }^{50}$.

E em Anacreonte em três [casos] (Fr. 359 PMG):

Cleóbulo amo,

por Cleóbulo enlouqueço e

para Cleóbulo olho.

Em Arquíloco, o nome significativo "Leófilo" pode indicar alguém cujo poder lhe foi conferido pela "tropa" (laós) à qual ele é "querido" (phílos). Alguns historiadores sustentam que os mais antigos tiranos surgiram no período

próprio Giges; cf. Heródoto 1.14 e a Antologia Palatina 7.709. Para a tirania arcaica, cf. Aristóteles (Pol. 5.1310bss), Murray (1983: 132-43) e Andrews (1956: 20ss).

$46 \Lambda \varepsilon \dot{\varphi} \varphi \imath \lambda o s$ Tarditi (1968)

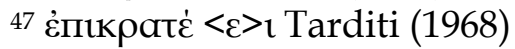

$48 \Lambda \varepsilon \dot{\omega} \varphi \imath \lambda o s$ Tarditi (1968)

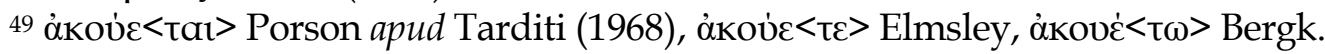

50 Há outro poliptoto em Arquíloco Fr. 177 IEG, onde Zeus é invocado pelo nome e depois pelo pronome de segunda pessoa singular respectivamente no acusativo, nominativo e dativo. Tarditi (1968) cita como paralelo os versos cômicos Adesp. 1325 (III p. 629 Kock) que não formam, porém, um poliptoto, mas são apenas anafóricos: Mntioxos $\mu \varepsilon \dot{\varepsilon} v$ yà $\rho$

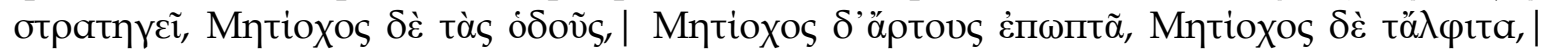

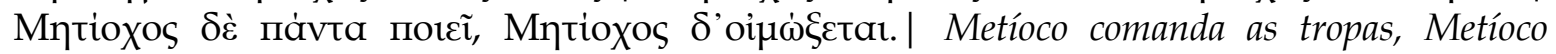
comanda as estradas/Metíoco assa pães, Metíoco assa cevada,/Metíoco faz de tudo, Metíoco geme.

Heródoto, Unifesp, Guarulhos, v. 2, n. 2, Dezembro, 2017. p. 168-194 - 178 - 
arcaico "como inovadores ou empreendedores militares" 51 , dependendo do apoio das tropas para governar. Assim, Gallavotti (1949: 71) acredita que esses versos eram dirigidos contra um "verdadeiro týrranos". Mas é possível que Leófilo fosse simplesmente um tipo ou o codinome de algum general popular que se tornou alvo do escárnio do poeta.

Há também dentre os personagens com nomes significativos Cerícides (kērýks + ídess) o "filho do arauto" a quem o "eu-jâmbico" envia uma "triste mensagem" (Fr. 185 IEG) e talvez Cerano ("comandante", "chefe" ou "senhor" 52), que teria sido poupado de um naufrágio por Poseidon hípio (Fr. 192 IEG).

Uma figura que se pode considerar histórica com menos incerteza, além de Glauco, é Péricles, contemporâneo de Arquíloco ${ }^{53}$ ao qual a célebre elegia (Fr. 13 IEG) se dirige e que, segundo Ateneu $1.7 f-8 b$, é censurado por seu comportamento nos simpósios, ${ }^{54}$ :

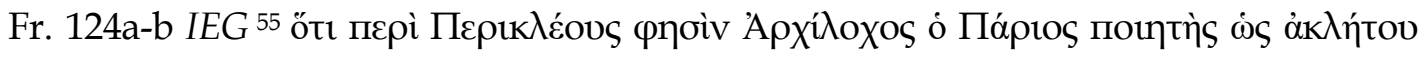

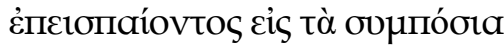

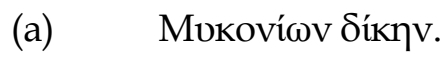

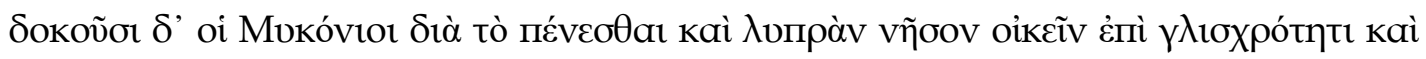

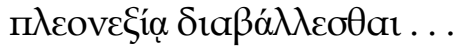

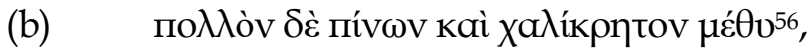

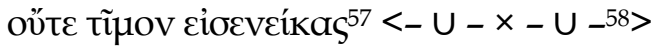

51 McGlew (1993: 2).

52 Corrêa (2010: 224): "Para Frisk (1960-1972), o termo significa "chefe de tropas", associado com herjann (o sobrenome de Odin), e Chantraine (1999, s.v. koipavos) o deriva de *koryo, que é uma "armada, um grupo de guerreiros". Assim, o "senhor Poseidon" poupa outro senhor, o "Cerano", por meio de um golfinho que, nas palavras de Opiano (Hal. 2.533) é um "grande senhor das tropas marinhas"

53 Cf. Aristides or. 46, ii.380.21 Dindorf.

54 Péricles: Arquíloco Fr. 13.1, 16, 28.4? IEG.

55 Não são numerosos os comentários acerca dos versos dos fragmentos $124^{\mathrm{a}}$-b IEG, cujo estabelecimento é complexo e problemático. Afora os comentários de Medaglia (1982) e Bossi $\left(1990^{2}\right)$, precisamente sobre os problemas textuais, há apenas algumas notas sobre o léxico em Hauvette (1905), Scherer (1964) e Page (1964), e um breve comentário em Fränkel (1975: 145),

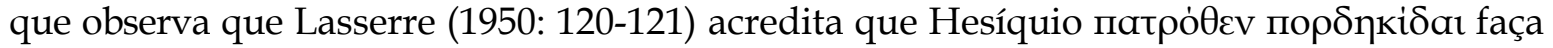
parte desse poema, na qual se narraria a fábula da mula (Bábrio 62 Perry). Cf. Medaglia (1982: 117), que cita Aristides Or. 46.11 p. 380 Dindorf.

56 Casaubon, $\mu \varepsilon \theta \dot{\omega} \omega \mathrm{v}$ codd.

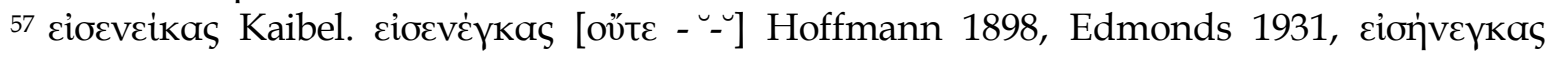




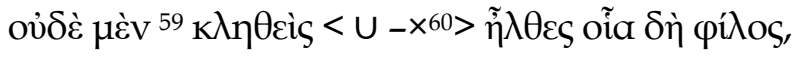

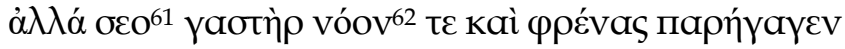

5 عiş ảvatóínv,

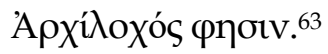

Arquíloco, o poeta pário, diz que Péricles, sem ser convidado, irrompia nos simpósios,

(a) à moda micônia

e parece que os micônios, por pobreza e por habitarem ilha miserável, tinham a reputação de serem avaros e gananciosos...

(b) bebendo muito vinho doce sem mistura, não contribuíste para as despesas (...) nem sendo convidado (...) vieste como um amigo, mas teu estômago desviou razão e juízo à sem-vergonhice,

diz Arquíloco." 64

Outros indivíduos nomeados em Arquíloco são o arquenáctida no fragmento 122.10 IEG, e talvez um Arthmiades (Fr. 29.2 IEG?), dos quais não temos mais informação. Nos poemas marciais, ainda há referência ao trácio

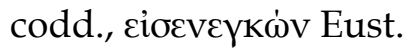

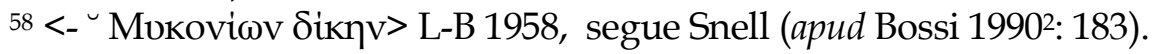

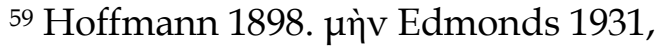

$60<\dot{\varepsilon} \sigma>\tilde{\eta} \lambda \theta \varepsilon \varsigma$ Casaubon, Edmonds 1931, L-B 1958, vं $\varphi ’ \dot{\eta} \mu \varepsilon \tilde{\omega v}$ Hiller-Crusius 1897, Hoffmann

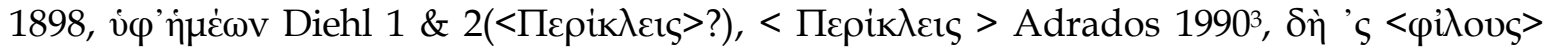

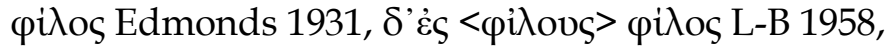

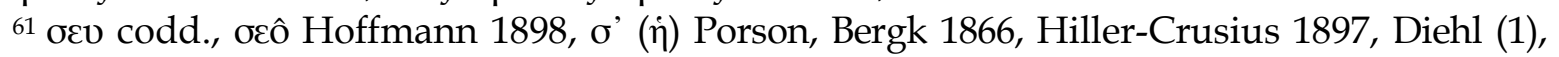
o’cv] Edmonds 1931, seu= Diehl 2, L-B 1958, Tarditi 1968, Adrados $1990^{3}$.

62 vóv codd., vóov Casaubon

${ }^{63}$ Há poucos comentários ao texto problemático de Arquíloco Fr. 124a -b IEG. Além de Medaglia (1982) and Bossi (19902), há notas lexicais em Hauvette (1905), Scherer (1964) e Page (1964), e um breve comentário em Fränkel (1975: 145), que observa que Lasserre (1950: 120-

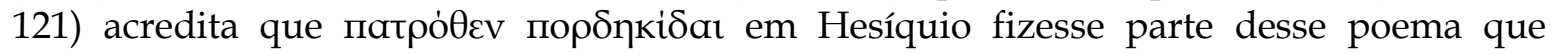
narraria a fábula da mula (Bábrio 62 Perry). Cf. Medaglia (1982: 117), que cita Aristides Or. 46. 11 p. 380 Dindorf.

${ }^{64}$ Como trata do simpósio e do comportamento de um conviva, o poema poderia ter como ocasião de performance o próprio simpósio, e foi justo por causa desta matéria que os versos nos foram transmitidos, em passagem difícil e corrupta, por Ateneu. 
Oisidres (Fr. 91.7?, 92 IEG), Erxias, citado duas ou três vezes (Fr. 88, 89.28, 110 IEG?), e um filho de Pisístrato (Fr. 93a. 4 IEG).

Contamos assim, dentre os 294 fragmentos de Arquíloco que nos restaram, excetuando todos os nomes de figuras divinas e heróis, um total de 31 nomes próprios de indivíduos (em 47 ocorrências) que povoam os versos e lhes conferem uma riqueza de tipos comparáveis com os que encontramos na comédia antiga: escravos, camponeses, artesãos, prostitutas, soldados, reis, generais, músicos e videntes, num espectro que vai do mais baixos aos mais altos estratos da sociedade ${ }^{65}$.

Quanto ao cidadão anónimo e a coletividade, como Arquíloco os representa? Em livro recente, Blok (2017) examina o conceito de cidadania em Atenas do período clássico. Como em seu artigo de 2005, Blok estuda o vocabulário da cidadania em Homero, Hesíodo, nos Hinos Homéricos, e depois passa direto a Sólon, Píndaro, Simônides e Teógnis. Antes dela, Lévy (1985) e Casevitz (2002), entres outros, ao estudar esse vocabulário, não tratam do corpus de mélicos, jâmbicos ou elegíacos menores do período arcaico. Trata-se, portanto, de um trabalho a ser feito, mas aqui nos restringiremos ao emprego de astoí, polítai e dèmos em Arquíloco.

Até a segunda metade do quinto século a. C., astoí e polítai só ocorrem no plural, e dentre os poetas arcaicos, astoí é muito mais comum ${ }^{66}$. No período clássico, a começar por Ésquilo, ocorre uma inversão e polítai passa a ser a designação mais frequente, que mais tarde será superada pelos gentílicos (como Athenaíoi para cidadãos de Atenas) ${ }^{67}$.

Qual a diferença entre astoí e polítai? Conforme Aristófanes de Bizâncio (s.v. àotós), não havia diferença entre os termos. Mas um escólio aos Trabalhos e Dias de Hesíodo (Schol. In Hes. Erg. 225), segundo Blok (2005: 17), pode oferecer uma pista para diferenciar as duas palavras, pois diz o seguinte: "o astós é oposto ao ksénos, e o que está longe de sua terra (apódēmos) é o contrário do éndèmos, que é o que está na sua terra". Assim, embora astós e polítēs sejam semelhantes, astós seria o termo marcado, empregado para fazer um contraste e para "dar ênfase ao que se quer indicar como pertencente a nós" 68 .

\footnotetext{
65 Cf. Pickard-Cambridge (1927), West (1974), Moulton (1981) e Rosen (1988).

66 Blok (2005: 15).

67 Blok (2005: 16).

68 Blok (2005: 17).
} 
No que restou de Arquíloco, há apenas duas ocorrências de astoí, nos fragmentos 170 e 133 IEG. Hefestião (Ench. 15. 2) traz em seu manual de métrica o fragmento $170 \mathrm{IEG}$, em que são mencionados "cidadãos" (astoî) e a "maioria" (hoi polloî):

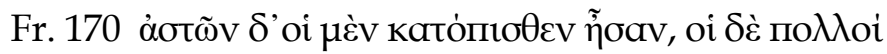

Fr. 170 dos cidadãos, uns estavam atrás, mas a maioria...

A segunda ocorrência encontra-se nos versos de Arquíloco Fr. 133 IEG preservados por Estobeu (4. 58. 4):

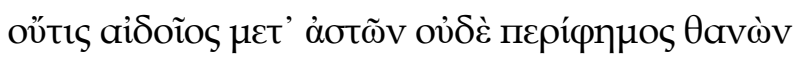

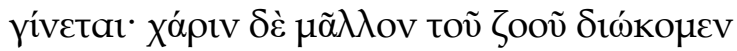

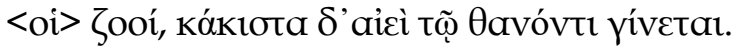

ninguém é respeitado dentre os cidadãos, nem louvado

quando morto. A graça, é antes a dos vivos que perseguimos,

<nós>, os vivos, e o pior sempre fica para o morto.

Infelizmente não há mais do que isso, que pouco nos informa sobre quem são ou o que faziam esses cidadãos. Não é evidente o uso marcado de astoí para fazer um contraste entre os que são da cidade e os estrangeiros no fragmento 170 IEG, não há indicação de gênero, nem de posição sociopolítica, trata-se de um termo que designa a coletividade dos habitantes de um centro urbano ${ }^{69}$. No fragmento 133 IEG, astoí pode ter sido empregado por ser mais comum, por causa da aliteração com aidô̂os, ou talvez para marcar esses mortos como "pertencentes a nós" e, por causa disso, dignos de respeito, louvor e graça (aidōs, phèmē, kháris) ${ }^{70}$.

Assim como astoí, polítai só ocorre no plural durante o período arcaico, com a exceção de um nome próprio em Homero. De forma semelhante, politai também é um coletivo que designa os habitantes da pólis, mas sem as implicações políticas de direitos e obrigações do cidadão que o termo terá mais tarde no quinto e, principalmente, do quarto século em diante ${ }^{71}$. A partir do

\footnotetext{
69 A palavra ásty, para cidade, poderia ser também usada para "enfatizar o centro urbano em contraste como campo ou vila vizinha" (Blok, 2005: 17).

70 Os versos expressam também o chamado "realismo" de Arquíloco em comparação com Tirteu Fr. 12. 23-34 IEG, nos quais se afirma que os mortos em combate recebem aidōs e são honrados após a morte (Cairns, 1993: 167, n. 64). Cf. Arquíloco Fr. 134 IEG: Escólio a Homero $O d$. 22. 412 "Não é sancionado por lei divina vangloriar-se sobre os mortos. Daí, Arquíloco diz: 'pois não é nobre zombar de homens mortos'”.

71 Blok (2005: 12).
} 
quarto século, politès, no singular, torna-se a forma mais comum de se referir a um cidadão livre com determinados direitos e deveres ${ }^{72}$.

Em Arquíloco, há só uma ocorrência do termo. Na Paz de Aristófanes, Hermes diz (vv. 603-4): "Ó sapientíssimos fazendeiros, minhas palavras ouvi | se desejais compreender como ela [a Paz] acabou"73. Um escólio aos versos de Aristófanes (Schol. ad loc., p. 95 Holwerda) esclarece:

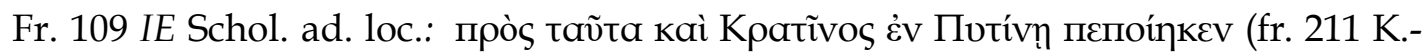

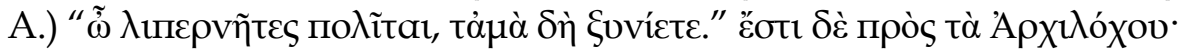

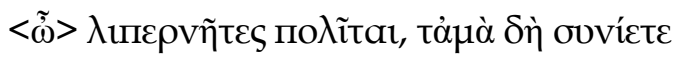

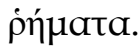

“Com relação a isso Cratino na Pitina (211 K.-A.) compôs: "Ó cidadãos desprovidos, minhas palavras ouvi". E isso vem de Arquíloco:

Ó cidadãos desprovidos, minhas palavras ouvi. ${ }^{74}$

Gerber (1999) sugere que esse fragmento 109 IEG de Arquíloco talvez pertencesse a uma exortação a uma emigração para Tasos. De fato, nada impede que fosse parte de um poema grave, como são muitos dos tetrâmetros trocaicos de Arquíloco, e a escassez de alimentos e de recursos é apontada como uma das causas dos movimentos migratórios no sétimo século a. C..

Observa-se, porém, que polítai neste fragmento 109 IEG de Arquíloco não revela gênero nem estatuto social e, como na maioria das ocorrências mais antigas, o termo é qualificado por um adjetivo que o define, já que a principio ele indica simplesmente os habitantes da pólis ${ }^{75}$. Vale notar que o discurso se inicia com uma interjeição, um adjetivo e o vocativo polítai, reproduzindo o início típico de um discurso político proferido para cidadãos reunidos em assembleia, como será frequente mais tarde nos oradores.

Uma outra palavra usada por Arquíloco para se referir à coletividade é dēmos. No quinto século a. C., em Atenas, dèmos era geralmente empregado para os

\footnotetext{
72 Blok (2005: 13-14).

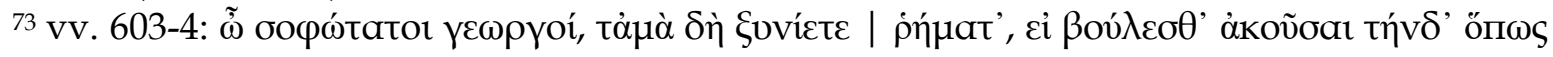

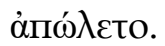

74 Segundo Gerber (1999), porém, oọẃtator em Aristófanes (Paz 603ss.) é aparentemente um erro. $\mathrm{O}$ adjetivo empregado na comédia seria também $\lambda \iota п \varepsilon \rho v \tilde{\tau} \tau \varsigma$, presente em Aristodemo 104 F 1 § 16, Diod. 12. 40. 6.

75 Blok (2005: 14).
} 
cidadãos livres de posição socioeconómica inferior e, a depender do contexto, poderia ser pejorativo ${ }^{76}$. Donlan (1970: 382), em estudo sobre o tema, afirma que em Homero ${ }^{77}$, Hesíodo e nos Hinos Homéricos a palavra não tem sentido depreciativo, nem sociopolítico, e que dèmos designava a comunidade como um todo, com a exclusão de seus líderes ${ }^{78}$. Mas se o dèmos não inclui os líderes, o termo faz uma distinção política.

O dèmos a princípio é um distrito, um espaço físico, e também as pessoas que nele habitam. No período arcaico, em Homero, Hesíodo e demais poetas, dèmos poderia ser empregado em oposição aos reis (basileís) e comandantes (LSJ sv $\delta \tilde{\eta} \mu o \varsigma)$, assim como o laós no exercito define a massa de soldados em contraste com os chefes e os heróis guerreiros. Nas comunidades arcaicas as "instituições são informais e dominadas pela elite". Mas um olhar de perto revela que o papel do dèmos e da assembleia é significante" (Raaflaub, 1998: 182), embora as decisões políticas, a guerra e a administração da justiça ficassem a cargo dos reis (basileís). Mais tarde, o dèmos passa a significar a "massa de cidadãos" que disputará o poder nas cidades com os membros da aristocracia, os chamados "nobres" (esthloî) e "bons" (agathoî) 79 .

Em Arquíloco, dèmos ocorre três vezes, nos fragmentos 14.1, 182.1 e 207 IEG. Hefestião (de poem. 7.2) cita os seguintes versos:

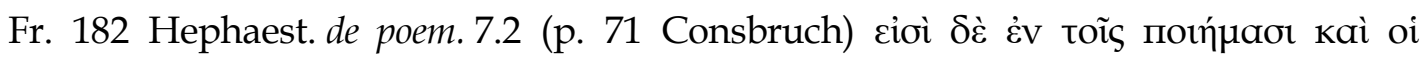

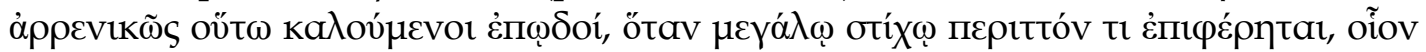

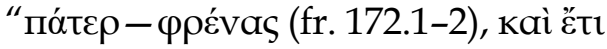

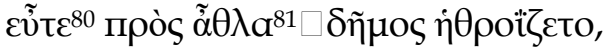

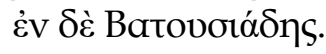

Hefestião de poem. 7.2: "Há também nos poemas os chamados epodos, com terminação masculina, quando ao verso longo se acrescenta um excedente, como no Fr. 172.1-2 e também:

Quando para os jogos o povo se reuniu

e, junto, Batusíades

Apesar de breve, não há no fragmento conotação pejorativa explícita quanto ao dèmos. Sabemos apenas que entre o povo reunido para jogos havia um tal

76 Donlan (1970: 382).

77 Exceto na Ilíada 2.198-206.

78 Donlan (1970: 385) nota, porém, a expressão de uma maior distância e tensão entre o dèmos e os seus líderes (os reis) em Hesíodo (Erga).

79 Hall (2007: 46, 48).

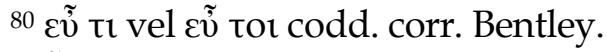

$81 \tilde{\alpha} \varepsilon \theta \lambda \alpha$ codd. corr. Fick. 
Batusíades. Mas esse, segundo Hesíquio (Arquíloco Fr. 183 IEG ${ }^{82}$ ), era um adivinho, filho de Seleu, e talvez o mesmo adivinho que, conforme conta Aristides, Arquíloco teria difamado:

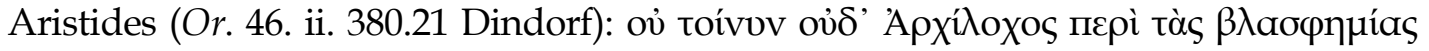

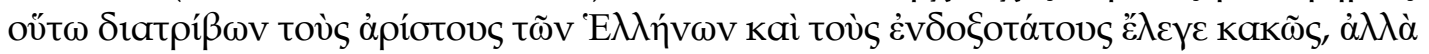

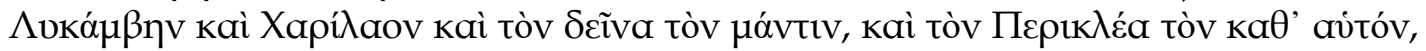

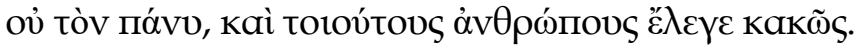

Portanto, nem mesmo Arquíloco, tão habituado à difamação, maldizia os melhores dentre os gregos, ou os mais estimados, mas Licambes, Carilau, um formidável adivinho [Fr. 182 IEG?] e Péricles, o de sua época, não o conhecido por todos; e de tais homens falou mal.

Se o patronímico Seleída em Arquíloco refere-se "aos Selos, vates de Zeus em Dodona" descritos na Ilíada 16. $235^{83}$ como profetas de pés sujos que dormem no chão, o fato deste Batusíades Seleída estar "entre o dèmos" talvez confira ao dèmos uma conotação negativa.

No fragmento 14 IEG de Arquíloco, que foi considerado por muitos como parte da chamada "Elegia a Péricles" (Fr. 13 IEG), um tal Esímedes é advertido:

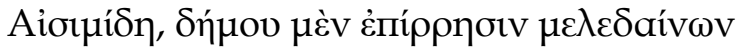

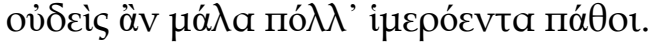

Esímides, com a censura do povo [dēmou] se importando, ninguém muitos prazeres teria.

Neste dístico, o falante aconselha Esímides a ignorar a censura do dèmos, e a palavra empregada para tal censura (epirrēsis) é glosada nos léxicos antigos (Órion 55.22 Sturtz, Et. Gen., Et. Mag.) por psógos e kakēgoría, que eram frequentemente associados aos jambos. Implícitos no conselho de desdenhar a censura do dēmos estão o poder e o temor que ela suscitava.

Quem é o falante e quem é o destinatário? Seriam líderes que diferenciam-se dos demais, o falante considerando Esímides e a si próprio como distintos do dèmos ao qual não devem dar ouvidos? Por outro lado, nada impede que o próprio Esímides fosse um homem do dèmos, e então os versos seriam um conselho para que não se desse importância à opinião alheia de modo geral.

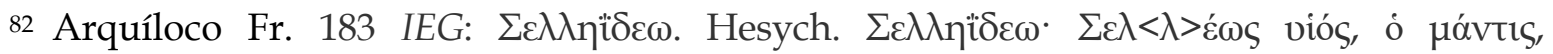
Batovotáon tò óvoua. (Seleída: filho de Seleu, o vidente chamado Batusíades).

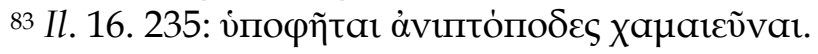


Se fosse, porém, alguém da heteria do poeta, o excesso de prazer que Esímides evita por temer a opinião do povo talvez não fosse muito diverso daquele que, mais tarde, Sólon censura com relação aos líderes de Atenas (Fr. 4. 7-10 IEG):

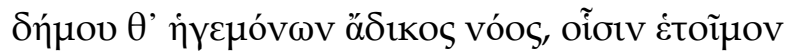

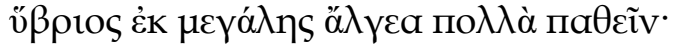

10

ov̉ yà

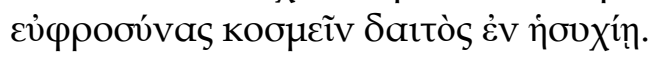

E a mente dos líderes do povo [dēmou] é injusta, os quais, por sua grande desmedida, têm por certo sofrer muitas dores; pois não sabem conter o excesso, nem os presentes festejos do banquete ordenar na quietude.

A terceira ocorrência de dèmos em Arquíloco foi registrada por Eustácio em seu comentário à Ilíada (23. 775 (iv.836. 1 V.d.Valk)). Eustácio não cita versos e apenas afirma que Arquíloco chama uma mulher (Neobula?) de "gorda nos tornozelos, mulher revoltante" 84 e "pública" (dèmos), isto é, "comum ao dèmos" (koinēn tōi dèmōi); "trabalhadora" e "escumalha", "por analogia à espuma do mar, ou algo semelhante" (Fr. 206-209 IEG).

Para Donlan (1970: 386 n.16), nas ocorrências de dèmos em Arquíloco o sentido é o da população total, indiferenciada, ao contrário do que ocorre em Tirteu, no fragmento 4.5 IEG onde, a seu ver, os "homens do dèmos" incluem todos os cidadãos livres exceto os líderes (como em Homero), e esses já representam "uma entidade constitucional", "com funções, direitos e responsabilidades definidos", podendo ser considerado como um "órgão no âmbito da pólis" 85 . Porém, se observarmos um outro fragmento de Tirteu, o Fr. 12.15 IEG, nele o termo é empregado com um sentido mais geral e sem a distinção de líderes, assim como no Fr. 1 IEG de Calino, onde dèmos também parece referir-se à cidade ou à população como um todo.

Portanto, apesar da escassa evidência, é possível que dèmos em Arquíloco distinguisse o povo de seus líderes, inclusive com uma conotação social. Em Álcman (Fr. 17. 4-8 PMG), porém, o emprego de dèmos revela clara diferenciação social. Segundo Ateneu (10. 416cd (ii 405s. Kaibel)), Álcman professa a sua gula nestes versos: um grande caldeirão logo estará repleto de sopa de ervilha...

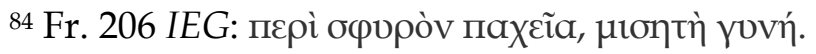

85 Donlan (1970: 385-6).
} 


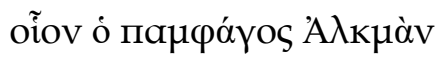

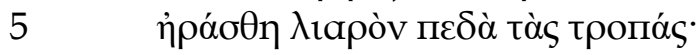

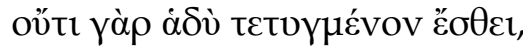

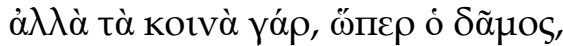

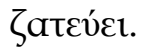
do tipo que Álcman, o come-tudo, gosta quente, após o solstício.
Pois ele não come doces confeitos,
mas o que é comum, como o povo [dāmos],
ele busca.

A caracterização do falante em Álcman como um "come-tudo" (pamphágos) que prefere sopa de ervilha, um dos pratos mais populares e qualificado aqui como algo "comum" de que o dāmos ( = dèmos) gosta, opõe o dèmos ("povo") àqueles que apreciam "doces confeitos".

Conclui-se que dèmos, na acepção de habitantes e não do território habitado, pode ser empregado desde Homero tanto de um modo mais geral e indiferenciado, ou com conotações sociopolíticas ${ }^{86}$. Quanto à acepção da palavra, se era pejorativa ou não, dependia do contexto, do gênero poético, da ocasião de performance e da ideologia do autor.

Por fim, são relativamente raras as ocorrências de dèmos em Arquíloco, em comparação com o número de personagens individualizados e nomeados (quer esses se referissem a pessoas reais, fossem codinomes significantes ou nomes de personagens puramente inventados). A maneira mais comum de se referir à coletividade em Arquíloco é pelo gentílico, que não faz distinções sociopolíticas e é mais concreto. Nos poemas há referências a tásios (Fr. 20, 91.44?, 92 IEG), náxios (Fr. 89.6 IEG), trácios (Fr. 42.1, 93.6 IEG), toronéus (Fr. 89.20 IEG), magnésios (Fr. 20 IEG), maronitas (Fr. 291 IEG), pan-helenos (Fr. 102 IEG) e bisaltas (Fr. 92 IEG?) ${ }^{87}$. Os gentílicos são empregados em Arquíloco para designar grupos e também indivíduos como um saio (Fr. 5.1 IEG), um frígio (Fr. 42.2 IEG) um cário (Fr. 216 IEG) e um carpátio (Fr. 248 $I E G)^{88}$. A presença e a frequência de nomes próprios, em contraste com os termos que designam o cidadão e/ou a coletividade, dependem em larga medida do gênero do discurso e da ocasião de performance.

\footnotetext{
${ }^{86}$ Cf. contra Donlan (1970: 387), para quem "até o final do sétimo século, dèmos não parece ter adquirido qualquer conotação social."

${ }^{87}$ Há também em Arquíloco referência a um vinho ismárico (Fr. 2.2 IEG), uma lei (ou modo musical?) crético (Fr. 232 IEG) e um asno de Priene (Fr. 43.2 IEG)

88 Habitante de ilha Cárpatos, entre Rodes e Creta.
} 
Embora Arquíloco mencione a ilha de $\operatorname{Paros}^{89}$, a sua terra natal, não nos restou nenhuma alusão ou interpelação aos pários. Não devemos nos fiar em argumentos ex silentio, mas uma hipótese plausível para a ausência de referências a "pários" em Arquíloco é que, se o poeta se dirigia diretamente a eles, quando não empregava os seus nomes próprios ou codinomes, ele usava pronomes ou astoí (e mais raramente politai) para se referir ao grupo, recorrendo aos gentílicos para marcar aqueles que não "pertencem a nós": os outros, os estrangeiros.

\section{Referências Bibliográficas}

Edições dos fragmentos de Arquíloco

ADRADOS, F. R. Líricos Griegos I: Elegiacos y Yambógrafos Arcaicos. Barcelona: Ediciones Alma Mater, 1956-1976 (1 ${ }^{\text {a }}$ ed.); Madrid: Consejo Superior de Investigaciones Científicas, 1990 (3a ed.).

BERGK, Th. Poetae Lyrici Graeci. vol II. Leipzig: B. G. Teubneri, 18824, 1915.

BRUNCK, R. F. P. Analecta Veterum Poetarum Graecorum. Strassburg: 1785.

BUCHHOLTZ, E. Anthologie aus den Lyrikern der Griechen. Leipzig: B. G. Teubner, 1886.

CRÖNERT, G. Archilochi Elegiae. (Auszug aus d. Habilitationsschrift), Göttingen, 1911.

DEGANI, E. Poeti greci giambici ed elegiaci. Milão, Mursia, 1977.

DIEHL, E. Anthologia Lyrica Graeca. Leipzig, B. G. Teubner, 1925 (1ª ed.), 1936 (2a ed.), 1952 (3a ed.).

EDMONDS, J. M. Greek Elegy and Iambus. Londres, Heinemann, 1931.

De FALCO, V. e A. de FARIA COIMBRA. Os Elegíacos Gregos de Calino a Crates. São Paulo: Brusco, 1941.

FARNELL, G. S. Greek Lyric Poetry: a complete collection of the surviving passages from the Greek songwriters. Londres: Longmans Green \& Co., 1891.

89 Tasos é a cidade mais frequentemente mencionada (Fr. 21.22, 89.19, 93.6, 96.97, 102, 103.2, 104.2, 228, 291, 295b IEG). 
GAISFORD, T. Poetae Minores Graeci. Vol I. Leipzig: Kuhn, 1823.

GERBER, D. E. Greek Iambic Poetry from the seventh to the fifth centuries B. C. Cambridge, Mass., Londres: Harvard University Press, 1999.

HILLER, E. Anthologia Lyrica Graeca sive Lyricorum Graecorum Veterum praeter Pindarum. Leipzig: B. G. Teubner, 1890.

HILLER, E. e CRUSIUS, O. Anthologia Lyrica Graeca sive Lyricorum Graecorum Veterum praeter Pindarum. Leipzig: B. G. Teubner, 1897 (4a ed.).

HUDSON-WILLIAMS, T. Early Greek Elegy. Cardiff: University of Wales Press Board \& Humphrey Milford, 1926.

LASSERRE, F. e BONNARD, A. Archiloque: Fragments. Paris: Belles Lettres, 1958.

LIEBEL, I. Archilochi Reliquiae. Leipzig: Sommer, 1812 (1a ed.); Viena: Johann Bartholomäus Zweck, 1818 (2a ed.).

MARZULLO, B. Frammenti della lirica greca. Florença: Sansoni, 1965-1967 (2a ed.).

SCHNEIDEWIN, F. G. Delectus Poesis Graecorum Elegiacae, Iambicae, Melicae. Göttingen: Vandenhoeck et Ruprecht, 1838.

SNELL, B. e FRANYÓ, S. Fruhgriechische Lyriker, II. Die Jambographen. Berlim: Akademie Verlag, 1972.

TARDITI, G. Archiloco. Roma: dell' Ateneo, 1968.

TREU, M. Archilochos. Munique: Ernst Heimeran, 1959

WEST, M. L., Iambi et Elegi Graeci ante Alexandrum cantati. Oxford: Oxford University Press, 1971 (1a ed.), 1998 (2a ed.).

\section{Estudos e comentários}

ANDREWES, A. The Greek Tyrants. London: Hutchinson's University Library; New York: Longmans, Green \& Co., 1956.

BARRON, J. P. e EASTERLING, P. E. Archilochus. In EASTERLING, P. e B. 
M. W. KNOX (edd.), The Cambridge History of Classical Literature I. Greek Literature. Cambridge: Cambridge University Press, 1985.

BATTEZZATO, L. Metre and Music. In BUDELMANN, F. (ed.) The Cambridge Companion to Greek Lyric. Cambridge: Cambridge University Press, 2009, pp.130-146.

BLOK, J. Becoming Citizens. Some Notes on the Semantics of "Citizen" in Archaic Greece and Classical Athens. Klio, vol. 87, 2005, pp. 5-40.

BLOK, J.Citizenship in Classical Athens. Cambridge: Cambridge University Press, 2017.

BOSSI, F. Studi su Archiloco. 2a ed. Bari: Adriatica, 1990.

BOWIE, E. Early Greek Iambic Poetry: The Importance of Narrative, In CAVARZERE, A., ALONI, A. \& A. BARCHIESI (edd.) Iambic Ideas; Essays on a Poetic Genre from Archaic Greece to the Late Roman Empire. Lanham, Boulder, Nova York, Oxford: Rowman \& Littlefield, 2001, pp. 1-27.

CAMPBELL, D. A. Greek Lyric Poetry: A Selection of Early Greek Lyric, Elegiac and Iambic Poetry. (2a ed.) Bristol, Bristol Classical Press, 1967-1982.

CASEVITZ, M. L'évolution de la citoyenneté en Grèce d'après le vocabulaire. In: RATTI, S. (ed.) Antiquité et citoyenneté. Actes du colloque international de Besançon (3-5 novembre 1999) Besançon: Institut des Sciences et Techniques de l'Antiquité (Collection «ISTA », 850), 2002, pp. 93-104.

CHANTRAINE, P. Dictionnaire étymologique de la langue grecque. Paris: Klincksieck, 1999 (2a ed.).

CORRÊA, P. Da Cunha. Armas e varões; A guerra na lírica de Arquíloco. 2a ed. rev. e aument. São Paulo: Edunesp, 2009.

CORRÊA, P. Da Cunha. Um Bestiário Arcaico. Fábulas e imagens de animais na poesia de Arquíloco. Campinas: Editora Unicamp, 2010.

DEGANI, E. e G. BURZACCHINI. Lirici Greci. Florença, La Nuova Italia, 1977.

DONLAN, W. Changes and Shifts in the Meaning of Demos. La Parola del passato. Rivista di studi antichi, vol. 25, 1970, pp. 381-95. 
DUARTE, A. da S. Duas comédias: Lisístrata e As tesmoforiantes. São Paulo: Martins Fontes, 2005.

FICK, A. F. "Die Sprachform der altionischen und altattischen Lyrik", Beiträge zur Kunde der Indogermanischen Sprachen, vol. 11, 1886, pp. 242-72; vol. 13, 1888, pp. 173-221.

FISHER, N. e H. van WEES (edd.) Archaic Greece: New Approaches and New Evidence. Londres: Duckworth, 1998.

FOWLER, R. L. The Nature of Greek Lyric. Three Preliminary Studies. Toronto, Buffalo: University of Toronto Press, 1987.

FRÄNKEL, H. Wege und Formen frühgriechischen Denkens. München: Beck, 1955.

FRÄNKEL, H. Early Greek Poetry and Philosophy: a history of Greek epic, lyric, and prose to the middle of the fifth century. Trad. M. Hadas e J. Willis. Oxford: Basil and Blackwell, 1975.

GALLAVOTTI, C. Il Tirrano di Archiloco. La Parola del passato. Rivista di studi antichi, vol. 4, 1949, pp. 69-71.

GENTILI, B. Poetry and its Public in Ancient Greece from Homer to the Fifth Century. Trad. T. Cole. Baltimore, Londres: Johns Hopkins University Press, 1988.

GENTILI, B. \& C. CATENACCI. Polinnia; Poesia Greca Arcaica. MessinaFirenze: Casa Editrice G. D’Anna, 2007 (3a ed.).

GERBER, D. E. (Euterpe: An Anthology of Early Greek Lyric, Elegiac and Iambic Poetry. Amsterdã: Adolf M. Hakkert, 1970.

HALL, J. M. Polis, Community, and Ethnic Identity, In SHAPIRO, H. A. (ed.) The Cambridge Companion to Archaic Greece. Nova York: Cambridge University Press, 2007, pp. 40-60.

HAUVETTE, A. Archiloque, sa vie et ses poésies. Paris: Fontemoing, 1905.

HOFFMANN, O. Die griechischen Dialekte in ihrem historischen Zusammenhange (III): Der Ionische Dialekt. Göttingen: Vandenhoeck \& Ruprecht, 1898.

HUMMEL, P. Les composés en lip(o)- dans la poésie lyrique grecque: étude 
d'un micro-système lexical. Philologus, vol. 141, 1997, pp. 145-148.

ITSUMI, I. What's in a line? Papyrus Formats and Hephaestionic Formulae. In FINGLASS, P. J., COLLARD, C. e RICHARDSON, N. J. (edd.) Hesperos. Studies in Ancient Greek Poetry presented to M. L. West on his Seventieth Birthday. Oxford: Oxford University Press, 2007, pp. 306-325.

KANTZIOS, I. The Trajectory of Archaic Greek Trimeters. Lieden, Boston: Brill, 2005.

LASSERRE, F. Les Épodes d' Archiloque. Paris: Belles Lettres, 1950.

LÉVY, E. Astos et polites d' Homère à Hérodote. Ktéma, vol. 10, [1985] 1988, pp. 53-66.

MARTINO, F. de e VOX, O. Lirica Greca. Vol. I: Prontuari e lirica dorica; Vol. II: Lirica ionica; Vol. III: Lirica eolica. Bari: Levante, 1996.

McGLEW, J. Tyranny and Political Culture in Ancient Greece. Ithaca e Londres: Cornell University Press, 1993.

MEDAGLIA, S. M. Note di esegesi archilochea. Roma: Accademia Nazionale dei Lincei, 1982.

MIRALLES, C. e J. PÒRTULAS. Archilochus and the Iambic Poetry. Roma: Dell' Ateneo, 1983.

MOULTON, C. Aristophanic Poetry. Göttingen: Vandenhoeck \& Ruprecht, 1981.

MURRU, F. Le polúptoton de Léophile. Eos, vol. 67, 1979, pp. 183-9.

NAGY, G. The Best of the Achaeans: Concepts of the Hero in Archaic Greek Poetry. Baltimore: Johns Hopkins University Press, 1979.

OSBORNE, R. Early Greek Colonization? The nature of Greek Settlement in the West. In FISHER, N. e H. van WEES (edd.) Archaic Greece: New Approaches and New Evidence. Londres: Duckworth, 1998, pp. 251-69.

PAGE, D. L. Archilochus and the Oral Tradition. In POUILLOUX, J. et al. (Org.) Archiloque: Sept exposés et discussions. Entretiens sur l'Antiquité Classique X (Vandoevres, Genebra, 26/8-3/9/1963). Genebra: Fondation Hardt, 1964, pp. 118-79. 
PICKARD-CAMBRIDGE, A. Dithyramb, Tragedy and Comedy. Oxford: Oxford University Press, 1927.

PIPPIN-BURNETT, A. Three Archaic Poets: Archilochus, Alcaeus, Sappho. Cambridge, Mass.: Harvard University Press, 1983.

RAAFLAUB, K. A. A historian's headache; How to read 'Homeric society'?, In FISHER, N. and H. van WEES (edd.) Archaic Greece: New Approaches and New Evidence. Londres: Duckworth, 1998, pp. 169-193.

RANKIN, H. D. Aristotle on Archilochus. L'Antiquité classique, vol. 46, 1961, pp. $165-8$.

RANKIN, H. D. Archilochus of Paros. Park Ridge, N.J.: Noyes Press, 1977.

ROSEN, R. M. Old Comedy and the Iambographic Tradition. Atlanta: Scholars Press, 1988.

ROSEN, R. M. Making Mockery; The Poetics of Ancient Satire. Oxford, Nova York: Oxford University Press, 2007.

SCHERER, A. Die Sprache des Archilochos, In POUILLOUX, J. et al. (Org.) Archiloque: Sept exposés et discussions. Entretiens sur l'Antiquité Classique $X$ (Vandoevres, Genebra, 26/8-3/9/1963). Genebra: Fondation Hardt, 1964, pp. 89-107.

SHAPIRO, H. A. (ed.) The Cambridge Companion to Archaic Greece. Nova York: Cambridge University Press, 2007.

WEST, M. L. Studies in Greek Elegy and Iambus. Berlim, Nova York: de Gruyter, 1974.

WEST, M. L. Greek Lyric Poetry. Trad. Oxford: Oxford University Press, 1993.

ZANETTO, G. Iambic Patterns in Aristophanic Comedy. In CAVARZERE, A., ALONI, A. e BARCHIESI, A. (edd.) Iambic Ideas; Essays on a Poetic Genre from Archaic Greece to the Late Roman Empire. Lanham, Boulder, Nova York, Oxford: Rowman \& Littlefield, 2001, pp. 65-76.

Os nomes dos autores antigos e de suas obras, quando abreviadas, seguem o padrão do Greek-English Lexicon de Liddell, Scott e Jones. 
Edições adotadas e as suas siglas

FGrH JACOBY, F. (ed.) Fragmente der griechischen Historiker. Berlim, Leiden: $\quad$ Brill, 1923-1958.

FHG MÜLLER, C. (ed.) Fragmenta Historicorum Graecorum. Paris: Didot, 1841-1870.

IEG WEST, M. L. (ed.) Iambi et Elegi Graeci ante Alexandrum cantati. Oxford: Oxford University Press, 1971 (1a ed.), 1998 (2a ed.).

K.-A. KASSEL, R. e AUSTIN, C. (ed.) Poetae Comici Graeci. Berlim, Nova York: de Gruyter, 1989.

PMG PAGE, D. L. (ed.) Poetae Melici Graeci. Alcmanis, Stesichori, Ibyci, Anacreontis, Simonidis, Corinnae, poetarum minorum reliqvias, carmina popvlaria et convivalia quaque adespota fervntor. Oxford: Oxford University Press, 1962.

V. VOIGT, E.-M. Sappho et Alcaeus: fragmenta. Amsterdã: Athenaeum, Polak \& Van Gennep, 1971.

LSJ A Greek-English Lexicon. Ninth Edition with Revised Supplement. Compilado por H. G. Liddell e R. Scott, revisto e aumentado por Sir Henry Stuart Jones, com o auxílio de Roderick McKenzie, suplemento editado por P. G. W. Glare com a assistência de A. A. Thompson. Oxford: Clarendon Press, 1996. 